\title{
Effects of Ceramide Accumulation in \\ Cardiomyocytes Derived from human-induced Pluripotent Stem Cells on Mitochondrial Function and Mitophagy
}

Mohamed Bekhite ( $\square$ Mohamed.el_Saied@med.uni-jena.de)

University hospital Jena https://orcid.org/0000-0003-0346-9181

Andres González-Delgado

Universitatsklinikum Jena Klinik fur Innere Medizin I Kardiologie Angiologie Pneumologie Internistische Intensivmedizin

Tom Kretzschma

Universitatsklinikum Jena, KIM I

Tina Müller

Universitatsklinikum Jena Klinik fur Anasthesiologie und Intensivtherapie

Jasmine M.F. Wu

Universitatsklinikum Jena Klinik fur Innere Medizin I Kardiologie Angiologie Pneumologie Internistische Intensivmedizin

\section{Tarek Bekfani}

Universitatsklinikum Jena Klinik fur Innere Medizin I Kardiologie Angiologie Pneumologie Internistische Intensivmedizin

\section{Marcus Franz}

Universitatsklinikum Jena Klinik fur Innere Medizin I Kardiologie Angiologie Pneumologie Internistische Intensivmedizin

\section{Maria Wartenberg}

Universitatsklinikum Jena Klinik fur Innere Medizin I Kardiologie Angiologie Pneumologie Internistische Intensivmedizin

\section{Markus Gräler}

Universitatsklinikum Jena Klinik fur Anasthesiologie und Intensivtherapie

\section{Boris Greber}

\section{Max-Planck-Institut fur Biophysik}

\section{Christian Schulze}

Universitatsklinikum Jena Klinik fur Innere Medizin I Kardiologie Angiologie Pneumologie Internistische Intensivmedizin 
Keywords: H-iPSCs, cardiomyocytes, cardiac lipotoxicity, ceramide accumulation, mitochondrial dysfunction

Posted Date: August 5th, 2020

DOI: https://doi.org/10.21203/rs.3.rs-47563/v1

License: (c) (i) This work is licensed under a Creative Commons Attribution 4.0 International License. Read Full License 


\section{Abstract}

\section{Background}

Oversupply of fatty acids (FAs) to cardiomyocytes (CMs) is associated with increased ceramide content and elevated the risk of lipotoxic cardiomyopathy. Here we investigate the role of ceramide accumulation on mitochondrial function and mitophagy in cardiac lipotoxicity using CMs derived from human-induced pluripotent stem cells (h-iPSCs).

\section{Methods and results}

Mature CMs derived from h-iPSCs exposed to the diabetic-like environment or transfected with plasmids overexpressing serine-palmitoyltransferase long chain base subunit 1 (SPTLC1), a subunit of the serinepalmitoyltransferase (SPT) complex, resulted in increased intracellular ceramide levels. Accumulation of ceramides impaired insulin-dependent phosphorylation of Akt through activating protein phosphatase $2 \mathrm{~A}$ (PP2A) and disturbed gene and protein levels of key metabolic enzymes including GLUT4, AMPK, PGC-1a, PPARa, CD36, PDK4, and PPARy compared to controls. Analysis of CMs oxidative metabolism using a Seahorse analyzer showed a significant reduction in ATP synthesis-related $\mathrm{O}_{2}$ consumption, mitochondrial basal respiration and respiratory capacity, indicating an impaired mitochondrial function under diabetic-like conditions or SPTLC1-overexpression. Further, ceramide accumulation increased mitochondrial fission regulators such as dynamin-related protein 1 (DRP1) and mitochondrial fission factor (MFF) as well as auto/mitophagic proteins LC3B and PINK-1 compared to control. Incubation of CMs with the specific SPT inhibitor (myriocin) showed a significant increase in mitochondrial fusion regulators the mitofusin 2 (MFN2) and optic atrophy 1 (OPA1) as well as p-Akt, PGC-1 a, GLUT-4, and ATP production. In addition, a significant decrease in auto/mitophagy and apoptosis was found in CMs treated with myriocin.

\section{Conclusions}

Our results suggest that ceramide accumulation has important implications in driving insulin resistance, oxidative stress, increased auto/mitophagy, and mitochondrial dysfunction in the setting of lipotoxic cardiomyopathy. Therefore, modulation of the de novo ceramide synthesis pathway may serve as a novel therapeutic target to treat metabolic cardiomyopathy.

\section{Background}

Cardiovascular complications in diabetes mellitus result from several mechanisms including intracellular calcium abnormalities, increased oxidative stress, lipotoxicity, and mitochondrial dysfunction [1]. However, deleterious effects and mechanisms of lipotoxicity and the underlying mechanism of mitochondrial function have yet to be elucidated in human cardiomyocytes (CMs). Disease modeling with human-induced pluripotent stem cell (h-iPSC) represents an interesting model to study the functional patterns, metabolic phenotype, and structural of CMs in medical research [2]. Both iPSCs and embryonic stem cells (ESC) are pluripotent but have different origins $[3,4]$. Using the h-iPSCs for generation and isolation of human 
cardiac cells will be interesting to investigate the underlying mechanisms of lipotoxicity in diabetic cardiomyopathy.

Previous studies showed that CMs derived from h-iPSCs display normal structure and physiological properties, which are equivalent to CMs derived from ESC. Also, they react to cholinergic/adrenergic stimulation and the chemicals that can act on different types of ion channels [5-7].

The rising occurrence of type 2 diabetes mellitus (T2DM) is emphatically connected with environmental factors such as a sedentary lifestyle and obesity [8]. Also, hereditary factors such as a family ancestry of diabetes and ethnic background are important for the development of the disease [9].

The adult heart can utilize fatty acids (FAs), glucose, pyruvate, amino acids, lactate, and ketone bodies for ATP production[10]. In addition, the adult heart adjusts uptake, metabolism, and oxidation of FAs to keep up ATP production and lipid signaling [11]. Moreover, there is $80 \%$ of free FA uptake in CMs is via CD36 transporter for oxidized and esterified to fatty acyl-CoA, which is then converted to acylcarnitine by carnitine palmitoyltransferase-1 (CPT-1) to enter to the mitochondria for energy production [12]. While glucose enters CMs via glucose transporters (GLUT), GLUT1 mediates insulin-independent and GLUT4 mediates insulin-dependent, which is phosphorylated through glycolysis and eventually yields pyruvate to be oxidized in the mitochondria for energy production [13]. T2DM is associated with increased circulating FAs promoting increased FA uptake while FA oxidation in CMs is impaired due to mitochondrial dysfunction [14]. This leads to the shunting of these FAs into alternative pathways for FA utilization and subsequently results in lipotoxicity and the accumulation of toxic lipid intermediates [15]. Toxic lipid metabolites such as ceramide and diacylglycerol (DAG) accumulate in diabetic-CMs leading to structural and functional impairment $[16,17]$. These also include apoptotic cell death [18] and activation of ROSsensitive proteases [19]. Ceramide can be synthesized by different synthesis pathways, de novo [20, 21], salvage [22], and sphingomyelin pathway [23]. Test and clinical information give proof of cardiac lipotoxicity in diabetes mellitus associated with cardiac dysfunction while several recent studies have demonstrated paths to decrease of toxic lipids as a way to improve cardiovascular function [11, 24, 25]. Further, there are clinical and animal studies that show the role of ceramides in diabetes and heart disease [26-28]. However, the role of ceramide in diabetic cardiomyopathy is not yet fully understood [16, 29].

Present work aims to analyze cellular and molecular mechanisms of cardiac lipotoxicity and the specific role of ceramides on mitochondrial function using CMs derived from h-iPSCs.

\section{Material And Methods}

Detailed material and methods are provided in the online data supplement.

\section{Maintenance and differentiation of h-iPSCs into CMs}

H-iPSC was generated from fibroblasts using Sendai viruses carrying the four Yamanaka factors [3], Oct3/4, Sox2, KIf4, and c-Myc (Life Technologies, Carlsbad, CA). The full characterization of h-iPSC was performed as described previously $[7,30]$. 
Differentiation of h-iPSCs into CMs which was induced using the protocol described here resulted in a high yield of ventricular h-iPSC-derived-CM production by using the sequential addition of small molecules [7, 30].

\section{Recapitulate a lipotoxic cardiomyopathy phenotype in vitro}

The h-iPSC-derived-CMs were exposed for three days to the diabetic-like medium (DM). The DM was composed of $10 \mu \mathrm{g} / \mathrm{mL}$ insulin, $0.2 \mathrm{mM}$ FAs (palmitic acid conjugated to BSA), $10 \mathrm{mmol} / \mathrm{L}$ glucose, 10 $\mathrm{nmol} / \mathrm{L}$ endothelin-1 and $1 \mu \mathrm{mol} / \mathrm{L}$ cortisol in DMEM [31].

\section{SPTLC1-overexpression plasmid}

The full-length human SPTLC1 gene was constructed into the p3XFLAG-CMV-7-BAP (Bacterial Alkaline Phosphatase, Sigma-Aldrich) expression vector. The empty vector was used as a control plasmid (CTRL). The SPTLC1 overexpression and control plasmids were transfected into the cells using Lipofectamine 3000 (Invitrogen/Thermo Fisher Scientific) following the manufacturer's instructions.

\section{Seahorse metabolic profiling}

Mitochondrial respiration and a complete bioenergetics profile were evaluated using a Seahorse analyzer (Agilent Technologies, Waldbronn, Germany). Single cells were plated on XF96 cell culture microplates (Agilent Technologies) at a density of $3.0 \times 10^{4}$ cells/well in medium and were kept for 24 hours at $37^{\circ} \mathrm{C}$ in a $\mathrm{CO}_{2}$ humidified atmosphere before assayed.

\section{Immunofluorescence studies}

Plated CMs were washed with ice-cold PBS and fix with methanol and acetone (7:3) for 30 min at -20 or $4 \%$ PFA at $4{ }^{\circ} \mathrm{C}$. Cells were then incubated with the respective primary antibody (Supplementary Material Table S1) and examined using a confocal laser scanning microscope 510 (cLSM; Zeiss, Jena, Germany).

\section{Mitochondrial and lysosomes dynamics analysis}

Cells were preincubated with MitoTracker green FM to detect mitochondria and LysoTracker Deep Red to detect lysosomes (both are from Thermo Fisher Scientific) following the manufacturer's instructions. Images were captured with a cLSM 510 (Zeiss), using ZEN image software (Zeiss) with the X-40 oil objective. 


\section{Western blot analysis}

Samples were washed twice with ice-cold PBS and lysed in lysis buffer as described previously [32]. Protein aliquots ( $20 \mu \mathrm{g}$ protein/lane) were separated in $8 \%$ or $12 \%$ SDS gels and transferred onto a nitrocellulose membrane. The images were captured by using the digital imaging system LAS 3000 (Fujifilm, Tokyo, Japan).

\section{Real-time-polymerase chain reaction (RT-PCR)}

Total RNA of h-iPSCs-derived-CMs was prepared using QIAshredder columns and an RNeasy mini kit (both from QIAGEN, Hilden, Germany) PCR amplification was performed using primer set as shown in the Supplementary Material Table S2 [33].

\section{Results}

\section{Cell culture model using h-iPSCs mimicking cardiac lipotoxicity phenotype in vitro}

H-iPSCs were cultured under cardiomyocyte (CM)-induction condition for 7 days and followed by further culturing in standard medium (SM) for another 20 days [30]. Flow cytometry (FCM) analysis showed that $80.53 \pm 6.56 \%$ of cells were a-actinin positive cells. Furthermore, ventricular marker myosin regulatory light chain 2 (MLC2v) positive cells represent $69.3 \pm 4.1 \%$ of the total number of cells (Fig. S1).

To mimic diabetic conditions in vitro, we exposed 28 days old CMs to diabetic-like medium (DM) for 3 days [31]. We observed the accumulation of intracellular lipid droplets $(497.2 \pm 168.87 \%$ in DM, $p<0.003)$

(Fig. 1a and 1b), as well as a loss of the regular sarcomeric pattern of CMs (Fig. 1a and 1c). Also, the result revealed that the cells had reduced MLC2v positive area (48.41 $\pm 19.36 \%$ in DM, $p<0.001)$ (Fig. $1 \mathrm{c}$ and $1 \mathrm{~d}$ ) while the a-actinin positive area was not affected (Fig. 1c and 1d). Furthermore, we found that the gene expression of cardiac brain natriuretic peptide $(B N P)$ was significantly up-regulated $(+155.06 \%, p<03$.) in CMs exposed to DM for 3 days (Fig. 1e). Moreover, we identified alteration in genes levels of mitochondrial biogenesis and genes related to glucose and fatty acid (FA) oxidative metabolism in the CMs exposed to diabetic-like conditions, such as glucose transporter 4 (GLUT4) $(-65.43 \%, p<0.001)$, peroxisome proliferator-activated receptor alpha $(P P A R a)(-83.61 \%, p<0.001)$, PPAR gamma coactivator-1 alpha ( $P G C$ 1a) $(-74.78 \%, p<0.001)$, carnitine palmitoyltransferase-IB $(C P T-1 B)(-63.57 \%, p<0.001)$, cluster of differentiation $36(C D 36)(+165.01 \%, p<0.02)$, pyruvate dehydrogenase kinase $4(P D K 4)(+272.69 \%, p<$ 0.002), and PPARY $(+189.09 \%, p<0.03)$ compare with untreated CMs (Fig. 1e). Diabetic-like conditions induced a decrease in the beating rate by $67.44 \pm 3.62 \%(p<0.03)$ (Fig. $1 \mathrm{f}$, online movies 1 and 2 ). This was accompanied by reduced expression of sarcoplasmic/endoplasmic reticulum $\mathrm{Ca}^{2+}$ ATPase 2a (SERCA2a) $(-73.79 \%, p<0.001)$ and altered relaxation-contraction dynamics with a significant increase in abnormal $\mathrm{Ca}^{2+}$ transient frequency $(16.7 \pm 3.2 \%)$ in CMs cultured in diabetic-like condition compared with the untreated $\mathrm{CMs}(3.5 \pm 1.6 \%)$ (Fig. $1 \mathrm{~g}$ and $1 \mathrm{~h}$, Online movies 3 and 4 ). 
To determine whether abnormal lipid accumulation occurs in h-iPSCs-derived-CMs cultured in DM can lead to cardiac lipotoxicity, we analyzed the ceramide content in CMs with mass spectrometry-based analysis. We found significantly increased in total ceramide levels (295.6 \pm 78.3 in SM versus $498.3 \pm$ $108.85 \mathrm{nM} / 10 \mu \mathrm{l}$ in DM, $p<0.02)$ in CMs exposed to the DM (Fig. 1i). To investigate the role of de novo ceramide synthesis pathway in cardiotoxicity, the protein level of SPTLC1 was detected by western blot. Assessment of the protein level of SPTLC1 $(p<0.002)$ in CMs showed a significant increase in h-iPSCsderived-CMs cultured in DM (Fig. 1j).

Accumulation of ceramides is known to increase mitochondrial ROS production [34]. Therefore, we evaluated mitochondrial oxidative stress in h-iPSCs-derived-CMs using MitoSOX staining. The result demonstrated an increased ROS production $(p<0.001)$ in CMs exposed to DM (Fig. 1k). Further, increased cleaved-caspase-3 level $(p<0.02)$ observed in the CMs exposed DM confirmed oxidative damage (Fig. $1 \mathrm{I})$. In conclusion, the presented data suggest that lipotoxicity and oxidative stress were induced in the CMs when exposed to a diabetic-like condition.

\section{Overexpression of SPTLC1 for endogenous ceramide induction}

To further investigate the role of ceramides in diabetic cardiotoxicity, CMs were transfected with SPTLC1overexpression plasmids, a subunit of the SPT complex critical for ceramide de novo synthesis. Protein levels of SPTLC1 increased $(p<0.002)$ after $24 \mathrm{~h}$ (Fig. 2a) compared to the control plasmid (CTRL). Moreover, a significant decrease in protein levels of SPTLC1 $(p<0.002)$ was noted in myriocin-treated SPTLC1-overexpression-CMs compared to non-treated CMs (Fig. 2a).

Overexpression of SPTLC1 in CMs resulted in increased total ceramide levels $(p<0.02)$. Among all ceramide species analyzed, it was found that the levels of long-chain (C16:00 and C18:00) and very longchain (C24:00) ceramide species were much in SPTLC1-overexpressed-CMs compared with CTRL-CMs (Table 1). Furthermore, higher levels of apoptosis and cellular oxidative stress were confirmed by increased levels of cleaved caspase-3 $(1.72 \pm 1.13, p<0.008)$ (Fig. $2 \mathrm{~b}$ ) and MitoSOX staining $(1.9 \pm 0.2, p<0.001)$ (Fig. 2c and 2d), respectively. However, the effect of SPTLC1-overexpression was abolished following myriocin treatment (Fig. 2a-d). 
Table 1

Ceramide species determined in SPTLC1-overexpressed CMs (nM/10 $\mu \mathrm{l}$ sample)

\begin{tabular}{|c|c|c|}
\hline $\mathrm{N}$-acyl chain & Empty (CTRL) \pm SD & $S P T L C 1 \pm S D$ \\
\hline C14:0 & $2,74 \pm 0,86$ & $1,82 \pm 0,7$ \\
\hline C16:0 & $53,57 \pm 5,59$ & $102,31 \pm 10,44^{*}$ \\
\hline C18:0 & $76,93 \pm 6,07$ & $166,17 \pm 8,1^{\star}$ \\
\hline $\mathrm{C} 20: 0$ & $16,31 \pm 7,54$ & $16,83 \pm 6,32$ \\
\hline $\mathrm{C} 22: 0$ & $26,50 \pm 12,06$ & $23,4 \pm 9,92$ \\
\hline C24:0 & $20,6 \pm 12,25$ & $97,88 \pm 26,42^{*}$ \\
\hline Total & $196.66 \pm 44.36$ & $408.5 \pm 62.1^{\star}$ \\
\hline
\end{tabular}

\section{Effects of SPTLC1-overexpression on mitochondrial structure and auto/mitophagy}

Next, we investigated the association between SPTLC1-overexpression and mitochondrial morphology and auto/mitophagy in CMs. For examination of the mitochondria and lysosomes, MitoTracker and LysoTracker were used, respectively. Our results revealed significant decreased $(p<0.001)$ MitoTracker signal (Fig. 3a and $3 \mathrm{~b}$ ) and increased $(p<0.001)$ LysoTracker area in the SPTLC1-overexpressed-CMs (Fig. 3a and 3c). Furthermore, these cells showed co-localization between LysoTracker and MitoTracker positive area $(p<0.001)$ (Fig. 3a and 3d). These findings suggested that SPTLC1-overexpression resulted in increased mitochondria fragmentation, which was associated with reduced mitochondria positive area and elevated mitophagy in CMs.

To further confirm this hypothesis, we analyzed mRNA expression levels of mitochondrial dynamic genes (Table 2). We investigated mitochondrial fission as indicated by dynamin-related protein 1 (DRP1) and mitochondrial fission factor (MFF) or mitochondrial fusion, as indicated by mitofusin 2 (MFN2) and optic atrophy 1 (OPA1), as well as auto/mitophagy markers such as microtubule-associated protein 1 light chain 3 beta (LC3B) and PETEN-induced kinase 1 (PINK-1) (Fig. 3e-g). 
Table 2

Mitochondrial dynamics mRNA expression levels in SPTLC1-overexpressed-CMs

\begin{tabular}{|c|c|c|c|c|}
\hline & $\begin{array}{l}\text { Empty (CTRL) } \\
\text { Untreated }\end{array}$ & SPTLC1Untreated & Empty (CTRL) + Myriocin & SPTLC1 + Myriocin \\
\hline \multicolumn{5}{|c|}{ Mitochondrial fission gene } \\
\hline$D R P 1$ & $1.0 \pm 0.13$ & $2.54 \pm 0.17^{*}$ & $1.04 \pm 0.11$ & $1.17 \pm 0.43^{\#}$ \\
\hline MFF & $1.0 \pm 0.12$ & $1.98 \pm 0.19 *$ & $1.17 \pm 0.43$ & $1.19 \pm 0.22^{\#}$ \\
\hline \multicolumn{5}{|c|}{ Mitochondrial fusion gene } \\
\hline MFN2 & $1.0 \pm 0.20$ & $0.56 \pm 0.14^{*}$ & $0.83 \pm 0.27$ & $1.08 \pm 0.19$ \\
\hline OPA1 & $1.0 \pm 0.18$ & $0.49 \pm 0.16 *$ & $0.86 \pm 0.36$ & $1.09 \pm 0.36$ \\
\hline
\end{tabular}

Overexpression of SPTLC1 in h-iPSCs-derived-CMs significantly increased levels of the DRP1 and MFF (Table 2). Furthermore, the auto/mitophagic protein levels of LC3B $(2.6 \pm 0.4, p<0.001)$, as determined by the ratio of lipidated LC3-II (autophagic) to non-lipidated LC3-I (non-autophagic), (Fig. 3e and 3f) and PINK$1(2.5 \pm 0.7, p<0.002)$ (Fig. 3 e and $3 \mathrm{~g}$ ) were elevated. Moreover, these cells showed decreased mRNA levels of the mitochondrial fusion MFN2 and OPA1 compared with CTRL-CMs (Table 2).

Incubation of SPTLC1-overexpression-CMs with myriocin had no effect on MFN2 and OPA1 expression compared to the myriocin-treated CTRL-CMs (Table 2). Parallel to this, our results showed a significant reduction in the DRP1 and MFF level in SPTLC1-overexpression-CMs treated with myriocin compared to the non-treated CMs (Table 2). Furthermore, decreased expression of LC3B $(p<0.001)$ (Fig. 3e and 3f) and PINK-1 $(p<0.002)$ (Fig. 3e and $3 \mathrm{~g}$ ) were noticed in myriocin-treated SPTLC1-overexpressed-CMs compared to the non-treated SPTLC1-overexpressed-CMs, indicating decreased auto/mitophagy.

\section{Mitochondrial function in SPTLC1-overexpression-CM}

We hypothesized that ceramide is a crucial signaling component controlling mitochondrial function. OCR and ECAR were measured continuously throughout the experimental period at baseline and stressed condition using a Seahorse analyzer (Fig. 4a and 4b). We observed a reduction in FA ß-oxidation (Fig. 4a) and glucose oxidation (Fig. 4b). Furthermore, decreased mitochondrial basal respiration (18.8 \pm 2.18 versus $8.0 \pm 1.26, p<0.01)$, respiratory capacity $(31.87 \pm 2.2$ versus $10.32 \pm 1.3, p<0.01)$, and ATP production (15.41 \pm 2.37 versus $6.84 \pm 0.77, p<0.01$ ) (Fig. $4 \mathrm{c}$ and $4 \mathrm{~d}$ ) were observed, indicating an impaired mitochondrial function in the SPTLC1-overexpressed-CMs. Incubation of SPTLC1-overexpressed-CMs with myriocin improved FA ß-oxidation (Fig. 4a) and glucose oxidation (Fig. 4b) as well as ATP production (6.84 \pm 0.77 versus $10.58 \pm 1.51, p<0.02$ ) compared to non-treated SPTLC1-overexpressed-CMs (Fig. $4 \mathrm{~d}$ ). 
In addition, protein levels of PGC-1a $(0.47 \pm 0.1, p<0.009)$ (Fig. 4 e and $4 f)$ and AMP-activated protein kinase (p-AMPKa) $(0.42 \pm 0.12, p<0.006)$ (Fig. $4 \mathrm{~g}$ and $4 \mathrm{~h}$ ) were decreased in SPTLC1-overexpressed-CMs. Interestingly, myriocin abolished the adverse effect of SPTLC1 overexpression in the CMs (Fig. 4e-h). This alteration in PGC-1a, a regulator of mitochondrial biogenesis, and p-AMPKa, a regulator of cellular energy and auto/mitophagy, confirmed our assumption that ceramide accumulation is involved in mitochondrial dysfunction.

\section{Effects Of Ceramide Accumulation On Cardiac Insulin Signaling}

Accumulation of ceramides in tissues leads to impairment of the Akt signaling by activating protein phosphatase 2A (PP2A) or protein kinase $\mathrm{C \zeta}$ (PKC $)$ [35, 36]. To further understand the signaling mediated by ceramide, the insulin-dependent phosphorylation of Akt and p-GLUT4 was measured after stimulating the CMs with insulin (100 nmol/L) [37]. The p-GLUT4 $(1.92 \pm 0.52, p<0.001)$ and p-Akt/Akt $(3.47 \pm 0.17, p<$ 0.001 ) (Fig. 5a and 5b) were significantly blocked in stimulated SPTLC1-overexpressed-CMs with $100 \mathrm{nmol} / \mathrm{L}$ insulin for $10 \mathrm{~min}$ compared with CTRL-CMs. Interestingly, the levels of p-Akt/Akt $(2.47 \pm 0.56$, $p<0.001)$ and $p$-GLUT4 $(1.83 \pm 0.680, p<0.03)$ were significantly increased by blockade of the serine SPTspecific inhibitor myriocin under the same condition (Fig. $5 \mathrm{a}$ and $5 \mathrm{~b}$ ). Together, the decreased phosphorylation of Akt (Ser 473) and p-GLUT4 in SPTLC1-overexpressed-CMs suggested a decreased insulin action.

Next, we analyzed whether inhibition of PP2A or PKC would interfere with the insulin-dependent phosphorylation of Akt. To this end, we used the PP2A and PKC inhibitors okadaic acid and BIM-1, respectively, in the presence or absence of insulin (Fig. 5c-f). Importantly, only the PP2A inhibitor significantly prevented the effect of SPTLC1 overexpression and the p-Akt increased significantly $(2.08 \pm$ $0.49, p<0.006$ ) compared to non-treated SPTLC1-CMs (Fig. $5 \mathrm{c}$ and $5 \mathrm{~d}$ ). Together, the western blot analysis revealed that activation PP2A in the SPTLC1-overexpressed-CMs resulted in the inability of insulin to activate the Akt.

\section{Myriocin and okadaic acid improve cardiac structure and function in diabetic-CMs}

We hypothesize that inhibition of ceramide accumulation or inactivation of PP2A results in improved diabetic-CMs functions. To prove this concept, $\mathrm{CMs}$ were cultured in DM either with myriocin or okadaic acid. Interestingly, we found that inhibition SPT with myriocin or PP2A with okadaic acid reduced diabeticinduced CMs intracellular lipid droplet accumulation (Fig. S2a and S2b) and improved cardiac contractility $(9.3 \pm 2.7$ beats $/ \mathrm{min}$ in DM versus $27.6 \pm 7.4$ beats $/ \mathrm{min}$ in $\mathrm{DM}+$ myriocin, $p<0.001)$ or PP2A $(9.3 \pm 2.7$ beats/min in DM versus $51.3 \pm 4.7$ beats/min in DM + okadaic, $p<0.001$ ) (Fig. S2c).

Also, inhibition of SPT or PP2A as well as mitochondrial complex I significantly reduced the effect of DMinduced intracellular ceramide accumulation in the CMs versus control, as shown in Table 3. C16:00 and C18:00 ceramides were significantly reduced by SPT inhibitor myriocin or PP2A inhibitor okadaic acid. Only 
rotenone, the inhibitor of mitochondrial complex I, had no significant effect on reducing the C18:00 ceramide level in CMs co-incubated in the diabetic-like condition (Table 3). No significant change was noticed in C24:00 ceramide in h-iPSCs-derived-CMs treated with myriocin or okadaic acid under diabeticlike condition compared to the CMs in SM (Table 3). Furthermore, our data showed that inhibition of ceramide accumulation could prevent oxidative injury (Fig. S2d-f). Parallel to this result, we showed that inactivated PP2A, during exposing the CMs to diabetic-like condition, was accompanied by a significant increase in the Akt insulin-sensitivity and glucose oxidation related proteins, p-Akt $(61.99 \pm 6.93 \%, p<$ $0.001)$, p-AMPK $(54.78 \pm 4.62 \%, p<0.001)$, p-GLUT4 $(82.78 \pm 23.17 \%, p<0.01)$ and PPARa $(71.16 \pm 13.19 \%$, $p<0.001)$ compared with DM (Fig. S2g-k). It was obvious that inhibition of the mitochondrial complex I did not significantly affect the levels of p-GLUT4, p-AMPK, and p-Akt following exposure to a diabetic-like condition for the same period (Fig. S2g-k).

Table 3

Alteration of the levels of different ceramide species in the h-iPSC-derived-CMs ( $\mathrm{nM} / 10 \mu \mathrm{l}$ sample)

\begin{tabular}{|c|c|c|c|c|c|c|c|c|}
\hline $\begin{array}{l}\mathrm{N}- \\
\text { acyl } \\
\text { chain }\end{array}$ & $\begin{array}{l}\text { Standard } \\
\text { medium } \\
\text { (SM) }\end{array}$ & $\begin{array}{l}\text { Diabetic } \\
\text { medium } \\
\text { (DM) }\end{array}$ & $\begin{array}{l}\text { Myriocin } \\
\text { (SM) }\end{array}$ & $\begin{array}{l}\text { Myriocin } \\
\text { (DM) }\end{array}$ & $\begin{array}{l}\text { Okadaic } \\
\text { acid } \\
\text { (SM) }\end{array}$ & $\begin{array}{l}\text { Okadaic } \\
\text { acid } \\
\text { (DM) }\end{array}$ & $\begin{array}{l}\text { Rotenone } \\
\text { (SM) }\end{array}$ & $\begin{array}{l}\text { Rotenone } \\
\text { (DM) }\end{array}$ \\
\hline C14:0 & $\begin{array}{l}4.75 \pm \\
2.35\end{array}$ & $\begin{array}{l}9.25 \pm \\
6.25\end{array}$ & $\begin{array}{l}2.38 \pm \\
0.521\end{array}$ & $\begin{array}{l}3.09 \pm \\
2.47\end{array}$ & $\begin{array}{l}3.93 \pm \\
2.92\end{array}$ & $\begin{array}{l}3.51 \pm \\
3.56\end{array}$ & $\begin{array}{l}1.31 \pm \\
0.24\end{array}$ & $\begin{array}{l}1.34 \pm \\
0.33\end{array}$ \\
\hline C16:0 & $\begin{array}{l}179.92 \pm \\
34.24\end{array}$ & $\begin{array}{l}335.73 \\
\pm \\
36.40 *\end{array}$ & $\begin{array}{l}126.13 \\
\pm 25.85\end{array}$ & $\begin{array}{l}179.12 \\
\pm 27.88^{\#}\end{array}$ & $\begin{array}{l}157.9 \pm \\
39.93\end{array}$ & $\begin{array}{l}177.86 \\
\pm \\
26.96^{\#}\end{array}$ & $\begin{array}{l}142.23 \pm \\
39.45\end{array}$ & $\begin{array}{l}155.57 \pm \\
41.74^{\#}\end{array}$ \\
\hline C18:0 & $\begin{array}{l}62.17 \pm \\
6.17\end{array}$ & $\begin{array}{l}89.27 \pm \\
9.40 *\end{array}$ & $\begin{array}{l}49.56 \pm \\
5.81\end{array}$ & $\begin{array}{l}55.03 \pm \\
8.63^{\#}\end{array}$ & $\begin{array}{l}52.62 \pm \\
7.60\end{array}$ & $\begin{array}{l}66.02 \pm \\
5.99^{\#}\end{array}$ & $\begin{array}{l}60.27 \pm \\
5.94\end{array}$ & $\begin{array}{l}76.5 \pm \\
7.11\end{array}$ \\
\hline C20:0 & $\begin{array}{l}15.92 \pm \\
5.67\end{array}$ & $\begin{array}{l}19.76 \pm \\
4.22\end{array}$ & $\begin{array}{l}14.81 \pm \\
7.76\end{array}$ & $\begin{array}{l}15.03 \pm \\
8.92\end{array}$ & $\begin{array}{l}16.26 \pm \\
8.47\end{array}$ & $\begin{array}{l}20.66 \pm \\
10.48\end{array}$ & $\begin{array}{l}15.09 \pm \\
6.85\end{array}$ & $\begin{array}{l}14.05 \pm \\
8.10\end{array}$ \\
\hline C22:0 & $\begin{array}{l}22.03 \pm \\
11.01\end{array}$ & $\begin{array}{l}26.88 \pm \\
10.36\end{array}$ & $\begin{array}{l}22.23 \pm \\
10.91\end{array}$ & $\begin{array}{l}23.62 \pm \\
13.34\end{array}$ & $\begin{array}{l}22.12 \pm \\
13.32\end{array}$ & $\begin{array}{l}25.48 \pm \\
14.46\end{array}$ & $\begin{array}{l}22.68 \pm \\
10.96\end{array}$ & $\begin{array}{l}21.42 \pm \\
12.42\end{array}$ \\
\hline C24:0 & $\begin{array}{l}20.97 \pm \\
7.62\end{array}$ & $\begin{array}{l}41.03 \pm \\
9.1 *^{*}\end{array}$ & $\begin{array}{l}19.28 \pm \\
9.99\end{array}$ & $\begin{array}{l}20.72 \pm \\
10.16\end{array}$ & $\begin{array}{l}19.94 \pm \\
11.34\end{array}$ & $\begin{array}{l}22.22 \pm \\
11.86\end{array}$ & $\begin{array}{l}20.02 \pm \\
12.56\end{array}$ & $\begin{array}{l}29.29 \pm \\
15.58\end{array}$ \\
\hline Total & $\begin{array}{l}305.76 \pm \\
67.08\end{array}$ & $\begin{array}{l}498.59 \\
\pm \\
83.11 *\end{array}$ & $\begin{array}{l}234.41 \\
\pm 60.81\end{array}$ & $\begin{array}{l}296.61 \\
\pm 71.43^{\#}\end{array}$ & $\begin{array}{l}272.76 \\
\pm 83.61\end{array}$ & $\begin{array}{l}315.76 \\
\pm \\
73.34^{\#}\end{array}$ & $\begin{array}{l}261.61 \pm \\
76.04\end{array}$ & $\begin{array}{l}298.17 \pm \\
85.31^{\#}\end{array}$ \\
\hline
\end{tabular}

Inhibition of ceramide accumulation rescues morphological and function in diabetic-CMs

In consistence with the results presented above, inhibition of the SPT and inactivate the PP2A improves mitochondrial function in diabetic-CMs. 
It was found that both myriocin and okadaic acid decreased the level of auto/mitophagy markers such as LC3-II (-1.41 fold in myriocin, $p<0.001$ and -0.72 fold in okadaic acid, $p<0.02)$ and PINK-1 ( -1.36 fold in myriocin, $p<0.001$ and -1.76 fold in okadaic acid, $p<0.001)$ in compared to untreated DM-CMs, as well as increased PGC-1a (+ 0.54 fold in myriocin, $p<0.04$ and +0.57 fold in okadaic acid, $p<0.004)$, the mitochondrial biogenesis regulator (Fig. 6a-d). To further confirm these findings, MitoTracker positivity and the ratio of LysoTracker and MitoTracker co-localized area were analyzed (Fig. 6e-h). Following myriocin or okadaic acid treatment, the DM-cultured cells showed a significant increase in mitochondria marker expression. Furthermore, a decrease of co-localization between the LysoTracker and MitoTracker area was observed, indicating a reduction in auto/mitophagy (Fig. 6h).

Interestingly, the toxic effect of ceramide on mitochondrial function was abolished in the presence of myriocin or okadaic acid under DM condition (Fig. 6i-I). Also, analysis of CM oxidative metabolism using a Seahorse analyzer showed increased mitochondrial activity and enhanced OCR and ECAR (Fig. $6 i$ and $6 j$ ). Furthermore, it was obvious that PP2A inhibition abolished the effect of ceramide and increased ATP production under the basal and stressed conditions (Fig. $6 \mathrm{k}$ and $6 \mathrm{I}$ ). In conclusion, the data presented here indicate a critical role of PP2A in the mitochondrial dysfunction of lipotoxic cardiomyopathy.

\section{Discussion}

In the present study, we address the effect of lipotoxicity and ceramide accumulation on cardiac metabolism and function using h-iPSCs-derived-CMs as a novel in vitro model of human CMs [7].

We show that exposure of h-iPSCs-derived-CMs to a diabetic-like conditions resulted in intracellular lipid accumulation and is associated with loss of the sarcomeric pattern of 28 days old CMs. We also found that these cells showed a significant reduction in MLC2v positive area, the ventricular cardiac muscle structure and function protein. These changes in cellular structure were accompanied by decreases in the beating rate of CMs. In addition, inhibition in the gene, such as SERCA2a, involved in the regulation of calcium contents leads to altered relaxation-contraction dynamics. This may result in a reduced beating rate as a consequence of impaired calcium transient frequency in $\mathrm{CMs}$ exposed to the diabetic-like environment. Furthermore, to determine whether lipid accumulation in h-iPSCs-derived-CMs leads to lipotoxicity, the ceramide content was analyzed. In comparison to the SM-cultured cells, there was a significant increase in long- and very-long-chain ceramide levels in CMs exposed to the diabetic-like condition indicated the lipotoxicity of CMs. It is known that obesity may increase lipid uptake in the heart and that the formation of lipid intermediates such as ceramides and DAG may increase mitochondrial ROS production, mainly from complex I, without ATP production. This leads to mitochondrial damage and consequently cardiac dysfunction in patients and the animal models [34, 38-41]. This is also supported by our observation that mitochondrial ROS production increased in CMs exposed to the DM. in addition, mitochondrial superoxide production is dependent on the accumulation of ceramide or PP2A activity. However, the mitochondrial complex I antioxidant, rotenone inhibitor, did not show a significant effect on reducing superoxide production, indicating the ceramide-PP2A pathway acts upstream of oxidative stress. Consistent with this result, the efficacy of antioxidant treatment has not been repeated in diabetic patients until now $[42,43]$. The inconsistency between clinical trials and animal experiments could result from the 
types of antioxidants used or the heterogeneity of patient populations [44-47]. Another possibility is that antioxidant drugs can't obstruct the continuous production of ROS [48]. We also observed that apoptosis was significantly reduced by inhibition of the SPT or PP2A. These results confirm that attenuated ceramide accumulation or PP2A inactivation can prevent mitochondrial dysfunction and oxidative injury under diabetic-like conditions.

As mentioned previously, ceramide accumulation decreases glucose oxidation through activation of PDK, which subsequently inhibits PDH enzyme complex. Therefore, the heart depends only on FA $\beta$-oxidation, which leads to increased oxidative stress structural damage of the heart $[49,50]$. In the present study, we showed a decrease in genes and proteins involved in glucose oxidation, FA ß-oxidation, and mitochondrial biogenesis in diabetic-CMs. The functional effect of altered expression in metabolism-related genes and proteins was confirmed by measurement of the mitochondrial respiration. The results support our hypothesis that a diabetic-like condition is involved in CMs metabolic dysfunction. Likewise, ceramide and its derivatives may contribute to insulin signaling defect, glucose uptake inhibition, and oxidative stress induction [36, 51]. Previous studies show that in the cardiomyopathy resulted from metabolic stress, the activity of PGC-1 $a$ and PPARa increases as an adaptive reaction, which derives the metabolism balance towards FA ß-oxidation [52, 53]. However, continuous metabolic stress reduces PGC-1a and its downstream signals, which are accompanied by repressed glucose and FA ß-oxidation. Such change leads to lipid overload in heart, insulin resistance, increased ROS production and apoptosis, and at the end results in cardiac dysfunction $[54,55]$.

Various studies have shown that mitochondrial structure and function depend on constant cycles of fission and fusion [56-58]. However, alterations in mitochondrial dynamics balance lead to mitochondrial dysfunction [59-62]. For example, increased fission causes mitochondrial fragmentation, which seems to be a necessary condition for apoptosis [63]. It is hypothesized that abnormal morphology structure of mitochondria causes diabetic cardiomyopathy, proposing a potential role of mitochondrial dynamics for pathological progression $[64,65]$. Nevertheless, it remains unclear how dysregulated mitochondrial structure and function contributed to the progress of diabetic cardiomyopathy.

Overexpression of SPTLC1-CMs resulted in an increased level of ceramide as well as cellular oxidative stress and apoptosis compared with CTRL-CMs. Furthermore, the SPTLC1-overexpressed-CMs showed reduced mitochondrial positive area and increased fragmented mitochondria, which are accompanied by an increase in auto/mitophagy. It has been demonstrated that physiological levels of autophagy are crucial for cell survival from oxidative stress by eliminating dysfunctional mitochondria [66, 67]. However, cell death may occur because of exorbitant levels of autophagy $[68,69]$. For that autophagy could be either preventative or destructive in the heart [58]. However, the role of autophagy, in diabetic cardiomyopathy remains inconclusive [70-72]. Mellor et al. found that in T2DM the autophagy is activated and contributes to cardiac pathology [73]. Consistently, the mice have deficient in insulin receptor substrates showed an increase in cardiac autophagy [74]. Consistent with this finding, we showed that overexpression of SPTLC1$\mathrm{CMs}$ or diabetic-CMs also significantly increases levels of the auto/mitophagy. Interestingly, a recent study has shown that lipid oversupply-induced mitophagy of CMs depends on specific ceramide enzyme-like CerS2 [16]. Furthermore, oversupply the adult primary CMs with saturated FA induces CerS5 and leads to 
autophagy and hypertrophy [75]. Consistent with these findings, we found that ceramide $\mathrm{N}$-acyl chain length $\mathrm{C} 18: 00$ and $\mathrm{C} 24: 00$ increased in diabetic-CMs and that mitochondrial fission and ROS production were significantly stimulated, which may lead to auto/mitophagy. However, our results differ from the work of Chen et al. who revealed that diabetic cardiomyopathy inhibits autophagy [76]. We hypothesized that ceramide is a crucial signaling component controlling mitochondrial function. To further confirm this hypothesis, mitochondrial respiration, and a complete bioenergetics profile was examined. We observed a significant reduction, in basal respiration, respiratory capacity, and ATP production, indicating an impaired mitochondrial function in the SPTLC1-overexpressed-CMs and diabetic-CMs. Moreover, blocking de novo synthesis of ceramide rescued mitochondrial function and related proteins in SPTLC1-overexpressed-CMs.

An opposite correlation between accumulation of ceramide and Akt activation has been reported in vivo and in vitro [77-80]. Interestingly, inhibition of ceramide biosynthesis restores the Akt activity and glucose uptake [35, 79]. Moreover, activation of phosphoinositide 3-kinase class (PI3K)-Akt-mTORC1 pathway by insulin signal not only stimulates protein synthesis but also to inhibits autophagy [81, 82].

In the present study, we showed that the association of ceramide with impaired Akt signaling is reversible and that either the de novo ceramide synthesis inhibitor or PP2A inhibitor activates Akt and significantly increase the PGC-1a, p-AMPKa and GLUT4 in SPTLC-1-overexpressed-CMs. This alteration in PGC-1a, a regulator of mitochondrial biogenesis and p-AMPKa, a regulator of cellular energy and auto/mitophagy, confirmed our proposed model that ceramide is involved in mitochondrial dysfunction and mitophagy.

\section{Conclusions}

Together, the key findings of present study are: (1) Ceramide accumulation causes CMs contractile dysfunction, impaired mitochondrial function, increased auto/mitophagy and cell apoptosis in CMs; (2) Ceramide de novo signaling pathway is responsible for negative regulation of phosphorylation of Akt in diabetic-like condition-treated of h-iPSCs-derived-CMs; (3) Inactivation of de novo ceramide synthesis and PP2A signaling pathway rescues the cardiac Akt sensitivity to insulin stimulation; (4) Restoration of Akt activity by the myriocin and okadaic acid improves the mitochondrial morphology and metabolism, revealing a potential strategy to treat the metabolic cardiomyopathy.

\section{Abbreviations}




\begin{tabular}{|ll|}
\hline BIM-1 & Bisindolylmaleimide I \\
\hline BSA & Bovine serum albumin \\
\hline CerS & Ceramide synthase \\
\hline CM & Cardiomyocyte \\
\hline CTRL & Control plasmid \\
\hline DAG & Diacylglycerol \\
\hline DM & Diabetic-like medium \\
DRP1 & Dynamin-related protein 1 \\
\hline ESC & Embryonic stem cells \\
FA & Fatty acid \\
FCCP & Carbonyl cyanide 4-(trifluoromethoxy) phenylhydrazone \\
\hline FCM & Flow cytometry \\
\hline h-iPSCs & Human-induced pluripotent stem cells \\
\hline Ins & Insulin \\
\hline MFF & Mitochondrial fission factor \\
\hline MFN2 & Mitofusin 2 \\
\hline MLC2v & Myosin regulatory light chain 2 ventricular \\
\hline OPA1 & Optic atrophy 1 \\
\hline PDK4 & Pyruvate dehydrogenase kinase 4 \\
\hline PP2A & Protein phosphatase 2A \\
\hline ROS & Reactive oxygen species \\
\hline SM & Standard manufacturer's maintenance medium \\
\hline SPT & Serine-palmitoyltransferase \\
\hline SPTLC & Serine-palmitoyltransferase long chain base subunit \\
\hline T2DM & Type 2 diabetes mellitus \\
\hline
\end{tabular}

\section{Declarations}

\section{Ethics approval and consent to participate}

Not applicable. 


\section{Consent for publication}

Not applicable.

\section{Availability of data and materials}

All associated data are available from the corresponding author on a reasonable request.

\section{Competing interests}

The authors declare that they have no competing interests.

\section{Funding}

This study was supported by the Interdisciplinary Center for Clinical Research (IZKF, J55) of the medical Faculty University Jena. PSC is supported by grants from the Else-Kröner-Fresenius Foundation and the National Institute of Health (HL114813).

\section{Authors' contributions}

MB as first author performed the experiments and was responsible for designing the study, collection and compilation of data, analysis of data, and in writing the manuscript. AGD, TK and MFW contributed in performing experiments and gene expression. TM and $M G$ analyzed the ceramide content in cells with mass spectrometry-based analysis. MF and MW helped in analyzing the data. BG performed the cells reprogramming. PCS designed and supervised the study and revised the manuscript. All authors read and approved the final manuscript.

\section{Acknowledgements}

We thank Dr. M. Förster, for the support during FCM procedures and Beate Schulze for her technical assistance, department of cardiology, University Hospital Jena. We also thank Dr. C. Beetz, University Hospital Jena, for kindly providing us with the BODIPY dye.

\section{References}

1. Rubler S, Dlugash J, Yuceoglu YZ, Kumral T, Branwood AW, Grishman A. New type of cardiomyopathy associated with diabetic glomerulosclerosis. Am J Cardiol. 1972;30(6):595-602.

2. Tanaka A, Yuasa S, Node K, Fukuda K. Cardiovascular Disease Modeling Using Patient-Specific Induced Pluripotent Stem Cells. Int J Mol Sci. 2015;16(8):18894-922.

3. Takahashi K, Tanabe K, Ohnuki M, Narita M, Ichisaka T, Tomoda K, Yamanaka S. Induction of pluripotent stem cells from adult human fibroblasts by defined factors. Cell. 2007;131(5):861-72.

4. Yu J, Vodyanik MA, Smuga-Otto K, Antosiewicz-Bourget J, Frane JL, Tian S, Nie J, Jonsdottir GA, Ruotti $\mathrm{V}$, Stewart R, et al. Induced pluripotent stem cell lines derived from human somatic cells. Science. 2007;318(5858):1917-20. 
5. Tanaka T, Tohyama S, Murata M, Nomura F, Kaneko T, Chen H, Hattori F, Egashira T, Seki T, Ohno Y, et al. In vitro pharmacologic testing using human induced pluripotent stem cell-derived cardiomyocytes. Biochem Biophys Res Commun. 2009;385(4):497-502.

6. Germanguz I, Sedan O, Zeevi-Levin N, Shtrichman R, Barak E, Ziskind A, Eliyahu S, Meiry G, Amit M, Itskovitz-Eldor $\mathrm{J}$, et al. Molecular characterization and functional properties of cardiomyocytes derived from human inducible pluripotent stem cells. J Cell Mol Med. 2011;15(1):38-51.

7. Bekhite MM, Gonzalez Delgado A, Menz F, Kretzschmar T, Wu JMF, Bekfani T, Nietzsche S, Wartenberg $\mathrm{M}$, Westermann M, Greber B, et al. Longitudinal metabolic profiling of cardiomyocytes derived from human-induced pluripotent stem cells. Basic Res Cardiol. 2020;115(4):37.

8. Astrup A. The good and the bad news: surgery vs. drug therapy. Obesity reviews: an official journal of the International Association for the Study of Obesity. 2008;9(1):1-3.

9. Nolan CJ, Damm P, Prentki M. Type 2 diabetes across generations: from pathophysiology to prevention and management. Lancet. 2011;378(9786):169-81.

10. Goldberg IJ, Trent CM, Schulze PC. Lipid metabolism and toxicity in the heart. Cell Metab. 2012;15(6):805-12.

11. Schulze PC, Drosatos K, Goldberg IJ. Lipid Use and Misuse by the Heart. Circulation research. 2016;118(11):1736-51.

12. Neely JR, Morgan HE. Relationship between carbohydrate and lipid metabolism and the energy balance of heart muscle. Annu Rev Physiol. 1974;36:413-59.

13. Kolwicz SC Jr, Tian R. Glucose metabolism and cardiac hypertrophy. Cardiovasc Res. 2011;90(2):194201.

14. Sobczak IS, A Blindauer A, Stewart CJ. A: Changes in Plasma Free Fatty Acids Associated with Type-2 Diabetes. Nutrients. 2019;11(9):2022.

15. Heather LC, Clarke K. Metabolism, hypoxia and the diabetic heart. J Mol Cell Cardiol. 2011;50(4):598605.

16. Law BA, Liao X, Moore KS, Southard A, Roddy P, Ji R, Szulc Z, Bielawska A, Schulze PC, Cowart LA. Lipotoxic very-long-chain ceramides cause mitochondrial dysfunction, oxidative stress, and cell death in cardiomyocytes. FASEB J. 2018;32(3):1403-16.

17. Chiu HC, Kovacs A, Ford DA, Hsu FF, Garcia R, Herrero P, Saffitz JE, Schaffer JE. A novel mouse model of lipotoxic cardiomyopathy. J Clin Invest. 2001;107(7):813-22.

18. Parra V, Eisner V, Chiong M, Criollo A, Moraga F, Garcia A, Hartel S, Jaimovich E, Zorzano A, Hidalgo C, et al. Changes in mitochondrial dynamics during ceramide-induced cardiomyocyte early apoptosis. Cardiovasc Res. 2008;77(2):387-97.

19. Steinberg SF. Oxidative stress and sarcomeric proteins. Circulation research. 2013;112(2):393-405.

20. Weiss B, Stoffel W. Human and murine serine-palmitoyl-CoA transferase-cloning, expression and characterization of the key enzyme in sphingolipid synthesis. European journal of biochemistry. 1997;249(1):239-47. 
21. Lee SY, Kim JR, Hu Y, Khan R, Kim SJ, Bharadwaj KG, Davidson MM, Choi CS, Shin KO, Lee YM, et al. Cardiomyocyte specific deficiency of serine palmitoyltransferase subunit 2 reduces ceramide but leads to cardiac dysfunction. J Biol Chem. 2012;287(22):18429-39.

22. Kitatani K, Idkowiak-Baldys J, Hannun YA. The sphingolipid salvage pathway in ceramide metabolism and signaling. Cellular signalling. 2008;20(6):1010-8.

23. Cingolani F, Futerman AH, Casas J. Ceramide synthases in biomedical research. Chem Phys Lipids. 2016;197:25-32.

24. Chokshi A, Drosatos K, Cheema FH, Ji R, Khawaja T, Yu S, Kato T, Khan R, Takayama H, Knoll R, et al. Ventricular assist device implantation corrects myocardial lipotoxicity, reverses insulin resistance, and normalizes cardiac metabolism in patients with advanced heart failure. Circulation. 2012;125(23):2844-53.

25. Schulze PC. Myocardial lipid accumulation and lipotoxicity in heart failure. Journal of lipid research. 2009;50(11):2137-8.

26. Lemaitre RN, Yu C, Hoofnagle A, Hari N, Jensen PN, Fretts AM, Umans JG, Howard BV, Sitlani CM, Siscovick DS, et al. Circulating Sphingolipids, Insulin, HOMA-IR, and HOMA-B: The Strong Heart Family Study. Diabetes. 2018;67(8):1663-72.

27. Meikle PJ, Summers SA. Sphingolipids and phospholipids in insulin resistance and related metabolic disorders. Nat Rev Endocrinol. 2017;13(2):79-91.

28. Lemaitre RN, Fretts AM, Sitlani CM, Biggs ML, Mukamal K, King IB, Song X, Djousse L, Siscovick DS, McKnight $B$, et al. Plasma phospholipid very-long-chain saturated fatty acids and incident diabetes in older adults: the Cardiovascular Health Study. Am J Clin Nutr. 2015;101(5):1047-54.

29. Walls SM, Cammarato A, Chatfield DA, Ocorr K, Harris GL, Bodmer R. Ceramide-Protein Interactions Modulate Ceramide-Associated Lipotoxic Cardiomyopathy. Cell reports. 2018;22(10):2702-15.

30. Zhang M, D'Aniello C, Verkerk AO, Wrobel E, Frank S, Ward-van Oostwaard D, Piccini I, Freund C, Rao J, Seebohm G, et al. Recessive cardiac phenotypes in induced pluripotent stem cell models of Jervell and Lange-Nielsen syndrome: disease mechanisms and pharmacological rescue. Proc Natl Acad Sci U S A. 2014;111(50):E5383-92.

31. Drawnel FM, Boccardo S, Prummer M, Delobel F, Graff A, Weber M, Gerard R, Badi L, Kam-Thong T, Bu $L$, et al. Disease modeling and phenotypic drug screening for diabetic cardiomyopathy using human induced pluripotent stem cells. Cell reports. 2014;9(3):810-21.

32. Bekhite MM, Finkensieper A, Binas S, Muller J, Wetzker R, Figulla HR, Sauer H, Wartenberg M. VEGFmediated PI3K class IA and PKC signaling in cardiomyogenesis and vasculogenesis of mouse embryonic stem cells. J Cell Sci. 2011;124(Pt 11):1819-30.

33. Bekhite MM, Muller V, Troger SH, Muller JP, Figulla HR, Sauer H, Wartenberg M. Involvement of phosphoinositide 3-kinase class IA (PI3K 110alpha) and NADPH oxidase 1 (NOX1) in regulation of vascular differentiation induced by vascular endothelial growth factor (VEGF) in mouse embryonic stem cells. Cell Tissue Res. 2016;364(1):159-74. 
34. Bugger $\mathrm{H}$, Abel ED. Molecular mechanisms for myocardial mitochondrial dysfunction in the metabolic syndrome. Clin Sci (Lond). 2008;114(3):195-210.

35. Chavez JA, Knotts TA, Wang LP, Li G, Dobrowsky RT, Florant GL, Summers SA. A role for ceramide, but not diacylglycerol, in the antagonism of insulin signal transduction by saturated fatty acids. J Biol Chem. 2003;278(12):10297-303.

36. Tonks KT, Ng Y, Miller S, Coster AC, Samocha-Bonet D, Iseli TJ, Xu A, Patrick E, Yang JY, Junutula JR, et al. Impaired Akt phosphorylation in insulin-resistant human muscle is accompanied by selective and heterogeneous downstream defects. Diabetologia. 2013;56(4):875-85.

37. Mackenzie RW, Elliott BT. Akt/PKB activation and insulin signaling: a novel insulin signaling pathway in the treatment of type 2 diabetes. Diabetes metabolic syndrome obesity: targets therapy. 2014;7:5564.

38. Shen X, Ye G, Metreveli NS, Epstein PN. Cardiomyocyte defects in diabetic models and protection with cardiac-targeted transgenes. Methods Mol Med. 2005;112:379-88.

39. Boudina S, Abel ED. Mitochondrial uncoupling: a key contributor to reduced cardiac efficiency in diabetes. Physiology (Bethesda). 2006;21:250-8.

40. Liu J, Shen W, Zhao B, Wang Y, Wertz K, Weber P, Zhang P. Targeting mitochondrial biogenesis for preventing and treating insulin resistance in diabetes and obesity: Hope from natural mitochondrial nutrients. Adv Drug Deliv Rev. 2009;61(14):1343-52.

41. Whaley-Connell A, Sowers JR. Indices of obesity and cardiometabolic risk. Hypertension. 2011;58(6):991-3.

42. Pickering RJ, Rosado CJ, Sharma A, Buksh S, Tate M, de Haan JB. Recent novel approaches to limit oxidative stress and inflammation in diabetic complications. Clin Transl Immunology. 2018;7(4):e1016.

43. Rahimi-Madiseh M, Malekpour-Tehrani A, Bahmani M, Rafieian-Kopaei M. The research and development on the antioxidants in prevention of diabetic complications. Asian Pac J Trop Med. 2016;9(9):825-31.

44. Heart Outcomes Prevention Evaluation. Study I, Yusuf S, Dagenais G, Pogue J, Bosch J, Sleight P. Vitamin E supplementation and cardiovascular events in high-risk patients. N Engl J Med 2000, 342(3):154-60.

45. Kennergren C, Mantovani V, Strindberg L, Berglin E, Hamberger A, Lonnroth P. Myocardial interstitial glucose and lactate before, during, and after cardioplegic heart arrest. Am J Physiol Endocrinol Metab. 2003;284(4):E788-94.

46. De Berardis G, Pellegrini F, Franciosi M, Belfiglio M, Di Nardo B, Greenfield S, Kaplan SH, Rossi MC, Sacco M, Tognoni G, et al. Quality of care and outcomes in type 2 diabetic patients: a comparison between general practice and diabetes clinics. Diabetes Care. 2004;27(2):398-406.

47. Johansen JS, Harris AK, Rychly DJ, Ergul A. Oxidative stress and the use of antioxidants in diabetes: linking basic science to clinical practice. Cardiovasc Diabetol. 2005;4:5. 
48. Kobayashi S, Liang Q. Autophagy and mitophagy in diabetic cardiomyopathy. Biochim Biophys Acta. 2015;1852(2):252-61.

49. Fillmore N, Mori J, Lopaschuk GD. Mitochondrial fatty acid oxidation alterations in heart failure, ischaemic heart disease and diabetic cardiomyopathy. Br J Pharmacol. 2014;171(8):2080-90.

50. Mori J, Alrob OA, Wagg CS, Harris RA, Lopaschuk GD, Oudit GY. ANG II causes insulin resistance and induces cardiac metabolic switch and inefficiency: a critical role of PDK4. Am J Physiol Heart Circ Physiol. 2013;304(8):H1103-13.

51. Fucho R, Casals N, Serra D, Herrero L. Ceramides and mitochondrial fatty acid oxidation in obesity. FASEB J. 2017;31(4):1263-72.

52. Liu W, Ruiz-Velasco A, Wang S, Khan S, Zi M, Jungmann A, Dolores Camacho-Munoz M, Guo J, Du G, Xie $L$, et al. Metabolic stress-induced cardiomyopathy is caused by mitochondrial dysfunction due to attenuated Erk5 signaling. Nat Commun. 2017;8(1):494.

53. Jiang Y, Huang W, Wang J, Xu Z, He J, Lin X, Zhou Z, Zhang J. Metformin plays a dual role in MIN6 pancreatic beta cell function through AMPK-dependent autophagy. Int J Biol Sci. 2014;10(3):268-77.

54. Li X, Liu Y, Ma H, Guan Y, Cao Y, Tian Y, Zhang Y. Enhancement of Glucose Metabolism via PGC-1alpha Participates in the Cardioprotection of Chronic Intermittent Hypobaric Hypoxia. Front Physiol. 2016;7:219.

55. Cheng CF, Ku HC, Lin H. PGC-1alpha as a Pivotal Factor in Lipid and Metabolic Regulation. Int J Mol Sci 2018, 19(11).

56. Tilokani L, Nagashima S, Paupe V, Prudent J. Mitochondrial dynamics: overview of molecular mechanisms. Essays Biochem. 2018;62(3):341-60.

57. Cao YP, Zheng M. Mitochondrial dynamics and inter-mitochondrial communication in the heart. Arch Biochem Biophys. 2019;663:214-9.

58. Chen D, Li X, Zhang L, Zhu M, Gao L. A high-fat diet impairs mitochondrial biogenesis, mitochondrial dynamics, and the respiratory chain complex in rat myocardial tissues. $J$ Cell Biochem. 2018;119(11):9602.

59. Suarez-Rivero JM, Villanueva-Paz M, de la Cruz-Ojeda P, de la Mata M, Cotan D, Oropesa-Avila M, de Lavera I, Alvarez-Cordoba M, Luzon-Hidalgo R, Sanchez-Alcazar JA. Mitochondrial Dynamics in Mitochondrial Diseases. Diseases 2016, 5(1).

60. El-Hattab AW, Suleiman J, Almannai M, Scaglia F. Mitochondrial dynamics: Biological roles, molecular machinery, and related diseases. Mol Genet Metab. 2018;125(4):315-21.

61. Archer SL. Mitochondrial dynamics-mitochondrial fission and fusion in human diseases. N Engl J Med. 2013;369(23):2236-51.

62. Disatnik MH, Hwang S, Ferreira JC, Mochly-Rosen D. New therapeutics to modulate mitochondrial dynamics and mitophagy in cardiac diseases. J Mol Med (Berl). 2015;93(3):279-87.

63. Karbowski M, Youle RJ. Dynamics of mitochondrial morphology in healthy cells and during apoptosis. Cell Death Differ. 2003;10(8):870-80. 
64. Galloway CA, Yoon Y. Mitochondrial dynamics in diabetic cardiomyopathy. Antioxid Redox Signal. 2015;22(17):1545-62.

65. Yoon Y, Galloway CA, Jhun BS, Yu T. Mitochondrial dynamics in diabetes. Antioxid Redox Signal. 2011;14(3):439-57.

66. Matsui Y, Takagi H, Qu X, Abdellatif M, Sakoda H, Asano T, Levine B, Sadoshima J. Distinct roles of autophagy in the heart during ischemia and reperfusion: roles of AMP-activated protein kinase and Beclin 1 in mediating autophagy. Circ Res. 2007;100(6):914-22.

67. Mei Y, Thompson MD, Cohen RA, Tong X. Autophagy and oxidative stress in cardiovascular diseases. Biochim Biophys Acta. 2015;1852(2):243-51.

68. Kroemer G, Levine B. Autophagic cell death: the story of a misnomer. Nat Rev Mol Cell Biol. 2008;9(12):1004-10.

69. Liu Y, Levine B. Autosis and autophagic cell death: the dark side of autophagy. Cell Death Differ. 2015;22(3):367-76.

70. Sciarretta S, Zhai P, Shao D, Maejima Y, Robbins J, Volpe M, Condorelli G, Sadoshima J. Rheb is a critical regulator of autophagy during myocardial ischemia: pathophysiological implications in obesity and metabolic syndrome. Circulation. 2012;125(9):1134-46.

71. Guo R, Zhang Y, Turdi S, Ren J. Adiponectin knockout accentuates high fat diet-induced obesity and cardiac dysfunction: role of autophagy. Biochim Biophys Acta. 2013;1832(8):1136-48.

72. Xu X, Hua Y, Nair S, Zhang Y, Ren J. Akt2 knockout preserves cardiac function in high-fat diet-induced obesity by rescuing cardiac autophagosome maturation. J Mol Cell Biol. 2013;5(1):61-3.

73. Mellor KM, Bell JR, Young MJ, Ritchie RH, Delbridge LM. Myocardial autophagy activation and suppressed survival signaling is associated with insulin resistance in fructose-fed mice. $\mathrm{J}$ Mol Cell Cardiol. 2011;50(6):1035-43.

74. Riehle C, Wende AR, Sena S, Pires KM, Pereira RO, Zhu Y, Bugger H, Frank D, Bevins J, Chen D, et al. Insulin receptor substrate signaling suppresses neonatal autophagy in the heart. J Clin Invest. 2013;123(12):5319-33.

75. Russo SB, Baicu CF, Van Laer A, Geng T, Kasiganesan H, Zile MR, Cowart LA. Ceramide synthase 5 mediates lipid-induced autophagy and hypertrophy in cardiomyocytes. J Clin Invest. 2012;122(11):3919-30.

76. Chen C, Yang S, Li H, Yin Z, Fan J, Zhao Y, Gong W, Yan M, Wang DW. Mir30c Is Involved in Diabetic Cardiomyopathy through Regulation of Cardiac Autophagy via BECN1. Mol Ther Nucleic Acids. 2017;7:127-39.

77. Pickersgill L, Litherland GJ, Greenberg AS, Walker M, Yeaman SJ. Key role for ceramides in mediating insulin resistance in human muscle cells. J Biol Chem. 2007;282(17):12583-9.

78. Sabin MA, Stewart CE, Crowne EC, Turner SJ, Hunt LP, Welsh GI, Grohmann MJ, Holly JM, Shield JP. Fatty acid-induced defects in insulin signalling, in myotubes derived from children, are related to ceramide production from palmitate rather than the accumulation of intramyocellular lipid. $\mathrm{J}$ Cell Physiol. 2007;211(1):244-52. 
79. Bachmann OP, Dahl DB, Brechtel K, Machann J, Haap M, Maier T, Loviscach M, Stumvoll M, Claussen $\mathrm{CD}$, Schick F, et al. Effects of intravenous and dietary lipid challenge on intramyocellular lipid content and the relation with insulin sensitivity in humans. Diabetes. 2001;50(11):2579-84.

80. Hajduch E, Balendran A, Batty IH, Litherland GJ, Blair AS, Downes CP, Hundal HS. Ceramide impairs the insulin-dependent membrane recruitment of protein kinase $B$ leading to a loss in downstream signalling in L6 skeletal muscle cells. Diabetologia. 2001;44(2):173-83.

81. Mizushima N. The pleiotropic role of autophagy: from protein metabolism to bactericide. Cell Death Differ. 2005;12(Suppl 2):1535-41.

82. Meijer AJ, Codogno P. Signalling and autophagy regulation in health, aging and disease. Mol Aspects Med. 2006;27(5-6):411-25.

\section{Figures}



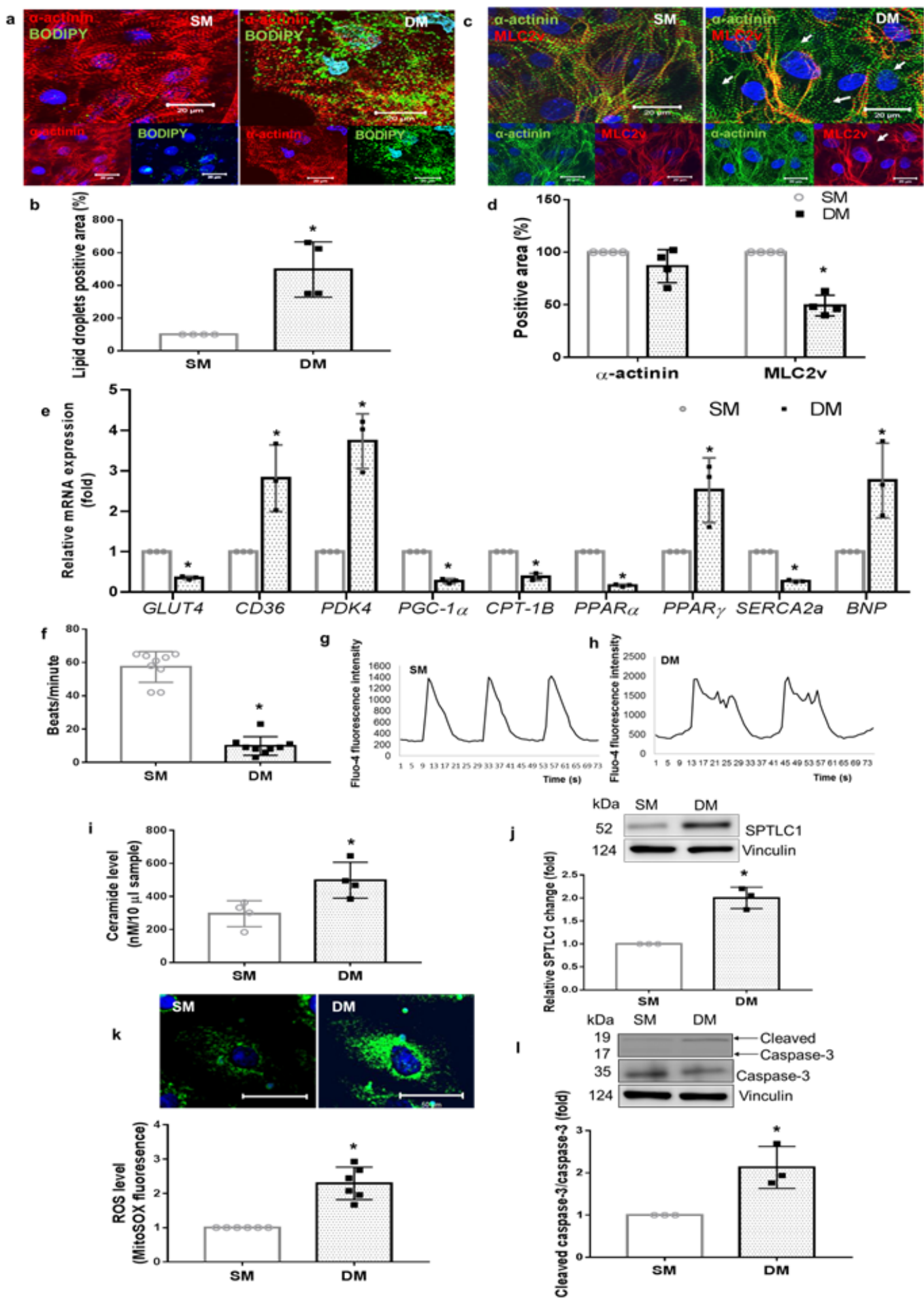

\section{Figure 1}

Characterization of diabetic effects on h-iPSCs-derived-CMs. a Representative immunofluorescence images of cardiac sarcomeric proteins, a-actinin (red) and lipid droplets, BODIPY (green). b Quantification of lipid droplets/field in the CMs cultured in DM compared to SM; $n=4$. c Cardiac sarcomeric proteins were stained with a-actinin (green) and MLC2v (red). Nuclei were stained with Hoechst (blue), and the scale bar represents $20 \mu \mathrm{m}$. d Quantification of $\mathrm{a}$-actinin and MLC2v positive area; $\mathrm{n}=4$. e Gene expression related to 
cellular metabolism and CMs functions were detected in CMs following exposure to DM and compared to $\mathrm{SM} ; \mathrm{n}=3$. $\mathrm{f}$ Quantification of beats per minute upon incubation of $\mathrm{CMs}$ with DM. Calcium transient frequency detected by fluo-4 fluorescence in h-iPSCs-derived-CMs. The image shown is the representative traces of spontaneous Ca2+ oscillations in h-iPSCs-derived-CMs cultured in SM (g) or DM condition (h); $n=3$. $i$ Total ceramide levels in CMs cultured in SM or DM condition was analyzed with mass spectrometrybased analysis; $n=4$. $j$ Representative western blot analysis of SPTLC1 protein level in the CMs. Analysis data shows increased SPTLC1 protein level in the CMs cultured in DM compared with SM; $n=3 . k$ Representative immunofluorescence images showing superoxide production in the mitochondrial of CMs. Nuclei were stained with Hoechst (blue), and the scale bar represents $50 \mu \mathrm{m}$. The analysis is presented as the fold change of MitoSOX fluorescence; $n=6$. I Detection of the protein level of cleaved caspase 3 by western blot in the CMs cultured in DM compared to SM-cultured CMs. The graph under the blot shows fold change (mean $\pm S D$ ) of 3 independent experiments. ${ }^{*} p<0.05$ using an unpaired two-tailed t-test compared to SM-CMs.

a
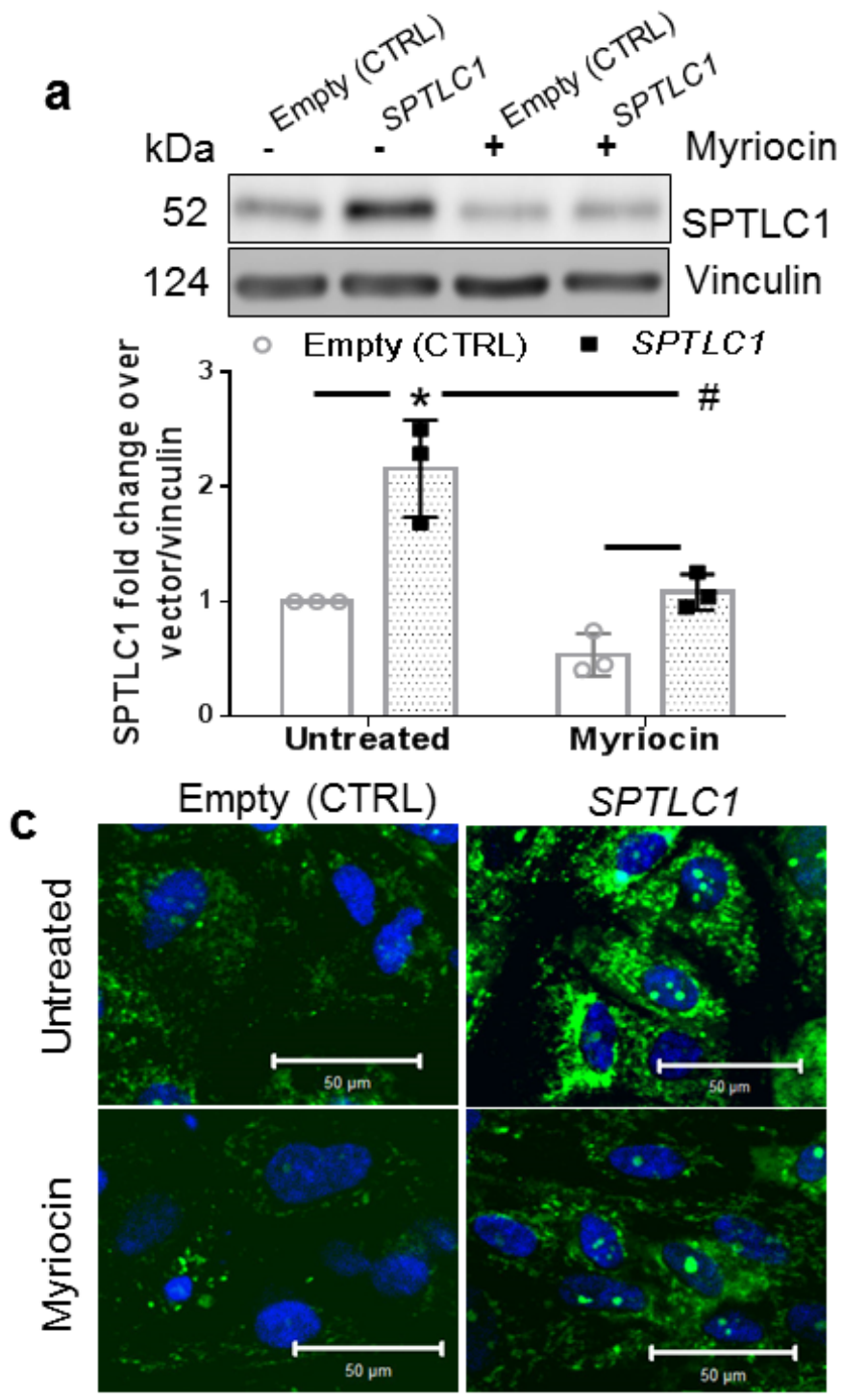

b
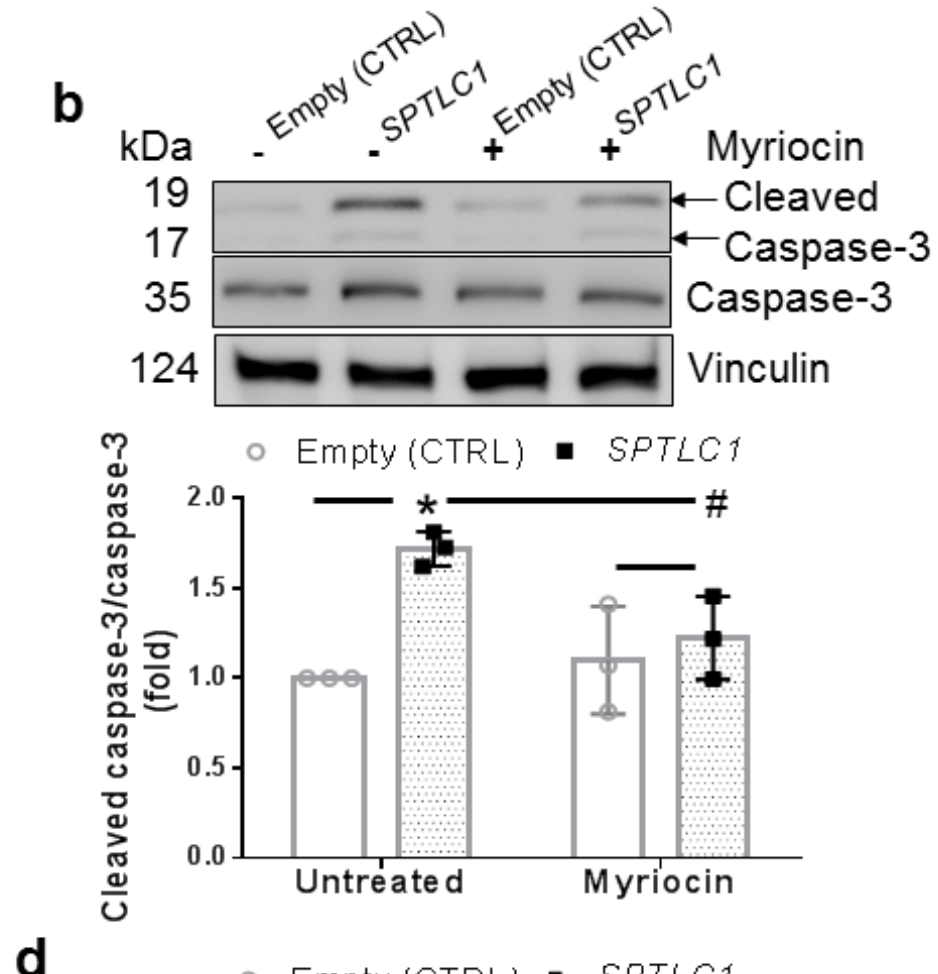

- Empty (CTRL) - SPTLCT

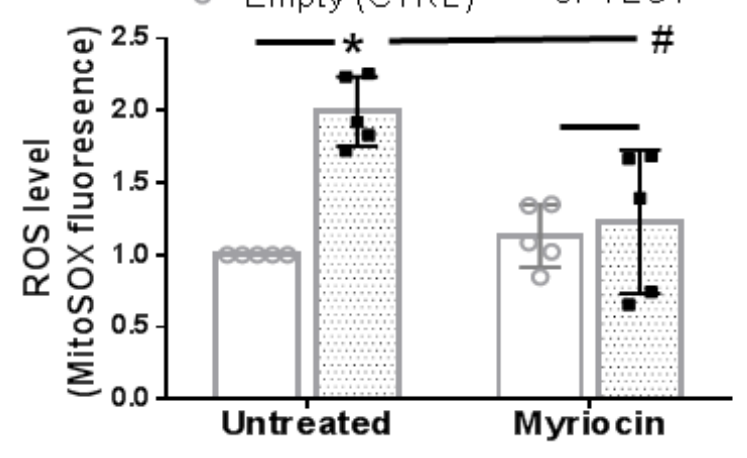

Figure 2 
Assessment of the changes in the h-IPSCs-derived-CMs transfected with SPTLC1-overexpression plasmids. a The protein level of SPTLC1 was detected using western blot in the h-iPSCs-derived-CMs 24 hours after transfection in the presence or absence of myriocin; $n=3$. b Comparison of cleaved caspase-3 protein levels in CTRL-CMs and SPTLC1-overexpressed-CMs in the presence or absence of myriocin; $n=3$. $c$

Representative images of the CTRL and SPTLC1-overexpressed-CMs stained with MitoSOX in the presence or absence of myriocin. Nuclei were stained with Hoechst (blue), and the scale bar represents $50 \mu m ; n=5$. $d$ Quantification of MitoSOX fluorescence intensity. * $p<0.05$ compared to CTRL-CMs and \# $p<0.05$ compared to SPTLC1-overexpression-CMs using two-way ANOVA Tukey's multiple comparisons test.

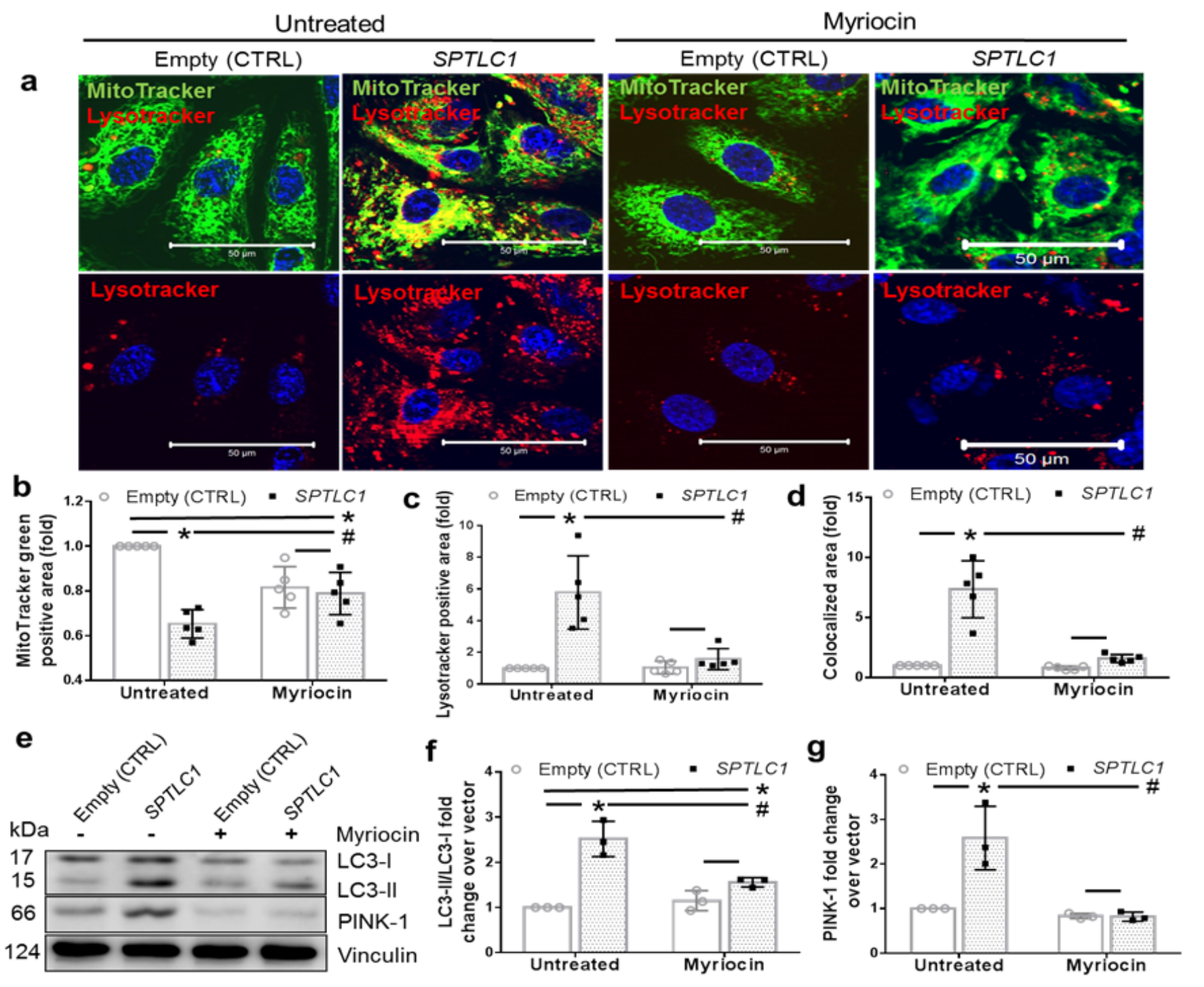

\section{Figure 3}

Association between SPTLC1-overexpression and mitochondrial morphology and auto/mitophagy in the iPSCs-derived-CMs. a Representative immunofluorescence images showing the cells stained with a mitochondrial marker (MitoTracker green) and lysosomes marker (LysoTracker red). Nuclei were stained with Hoechst (blue), and the scale bar represents $50 \mu \mathrm{m}$. Quantification of the positive areas of MitoTracker (b) and LysoTracker (c), as well as the ratio of co-localized LysoTracker and MitoTracker area (d) in SPTLC1-overexpressed-CMs, compared with CTRL-CMs in the presence or absence of myriocin; $n=5$. e 
Representative western blot results of LC3B and PINK-1 in the CTRL and SPTLC1-overexpressed-CMs in the presence or absence of myriocin. The ratio of lipidated LC3-II to non-lipidated LC3-I (f) and PINK-1 (g) fold change compared to CTRL-CMs in the presence or absence of myriocin; $n=3 .{ }^{*} p<0.05$ compared to CTRLCMs and \# $p<0.05$ compared to SPTLC1-overexpression-CMs using two-way ANOVA Tukey's multiple comparisons test.

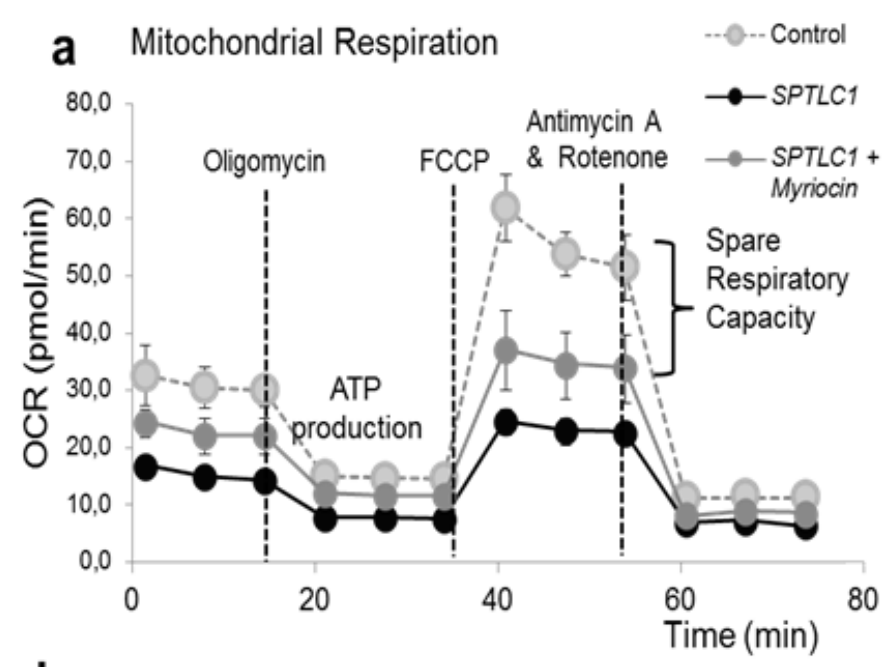

C $\mathrm{CControl} \backsim S P T L C 1$ aSPTLC1 + Myriocin
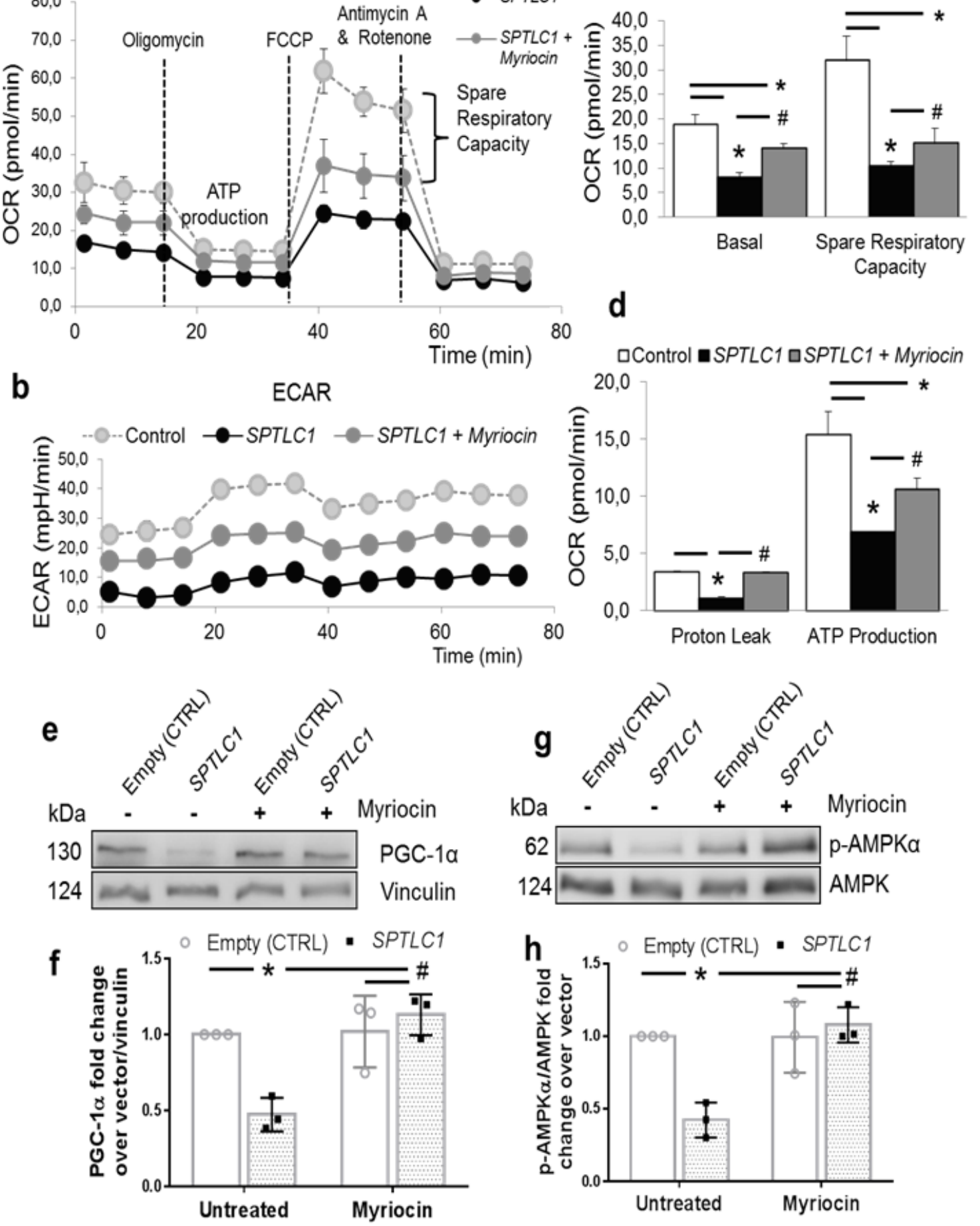

Figure 4 
Mitochondrial respiration and a complete bioenergetics profile of SPTLC1-overexpressing-CMs measured using a Seahorse analyzer. a FA $\beta$-oxidation determined through measurements of OCR. b Glycolysis determined through measurements of the ECAR. Statistical analysis basal respiration and respiratory capacity (c) as well as proton leak and ATP production (d). The protein level of PGC-1a (e and f) and pAMPKa ( $\mathrm{g}$ and $\mathrm{h}$ ) was detected by western blot in SPTLC1-overexpressing-CMs compared to the CTRL-CMs in the presence or absence of myriocin; $n=3$. * $p<0.05$ compared to CTRL-CMs and $\# p<0.05$ compared to SPTLC1-overexpression-CMs using two-way ANOVA Tukey's multiple comparisons test.
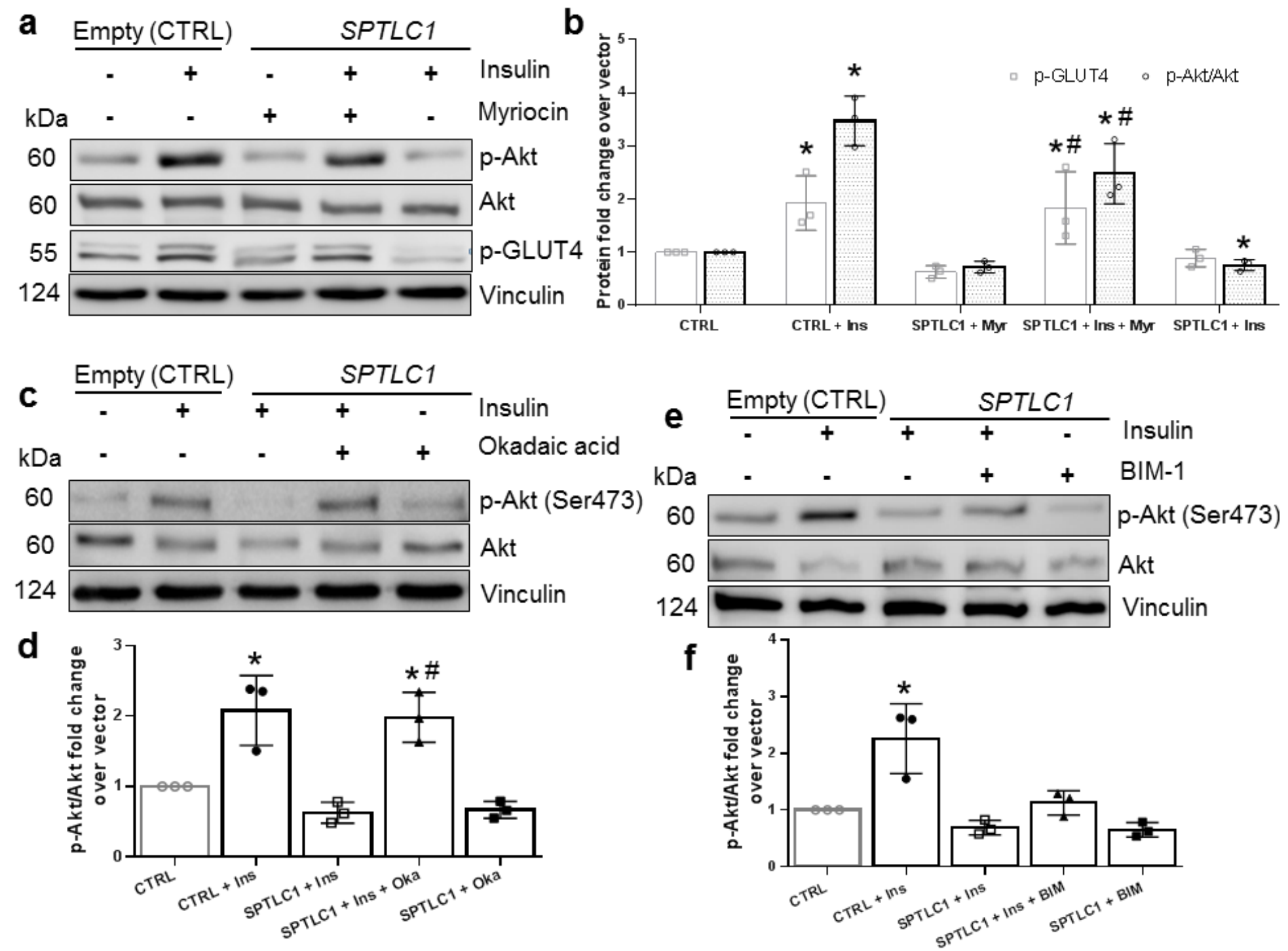

\section{Figure 5}

Accumulation of ceramide inhibits insulin-dependent phosphorylation of Akt. Insulin-dependent phosphorylation of Akt and p-GLUT4 measured by western blot after stimulating the CTRL-CMs, and SPTLC1-overexpressed-CMs with insulin (Ins, $100 \mathrm{nmol} / \mathrm{L}$ ) for $10 \mathrm{~min}$ in the presence or absence of myriocin (Myr). a and b Protein change of p-Akt (Ser 473)/total Akt and p-GLUT4 in different experimental conditions was statistically analyzed. Level of p-Akt (Ser 473)/total Akt in the CTRL-CMs, and SPTLC1overexpressed-CMs following stimulation with insulin (Ins, $100 \mathrm{nmol} / \mathrm{L}$ ) for $10 \mathrm{~min}$ in the presence or absence of okadaic acid (oka), the PP2A inhibitor (c and d) as well as in the presence or absence of BIM-1, 
the PKC inhibitor (e and f). * $p<0.05$ compared to CTRL-CMs and \# $p<0.05$ compared to SPTLC1-CMs using one-way ANOVA Tukey's multiple comparisons test; $\mathrm{n}=3$.

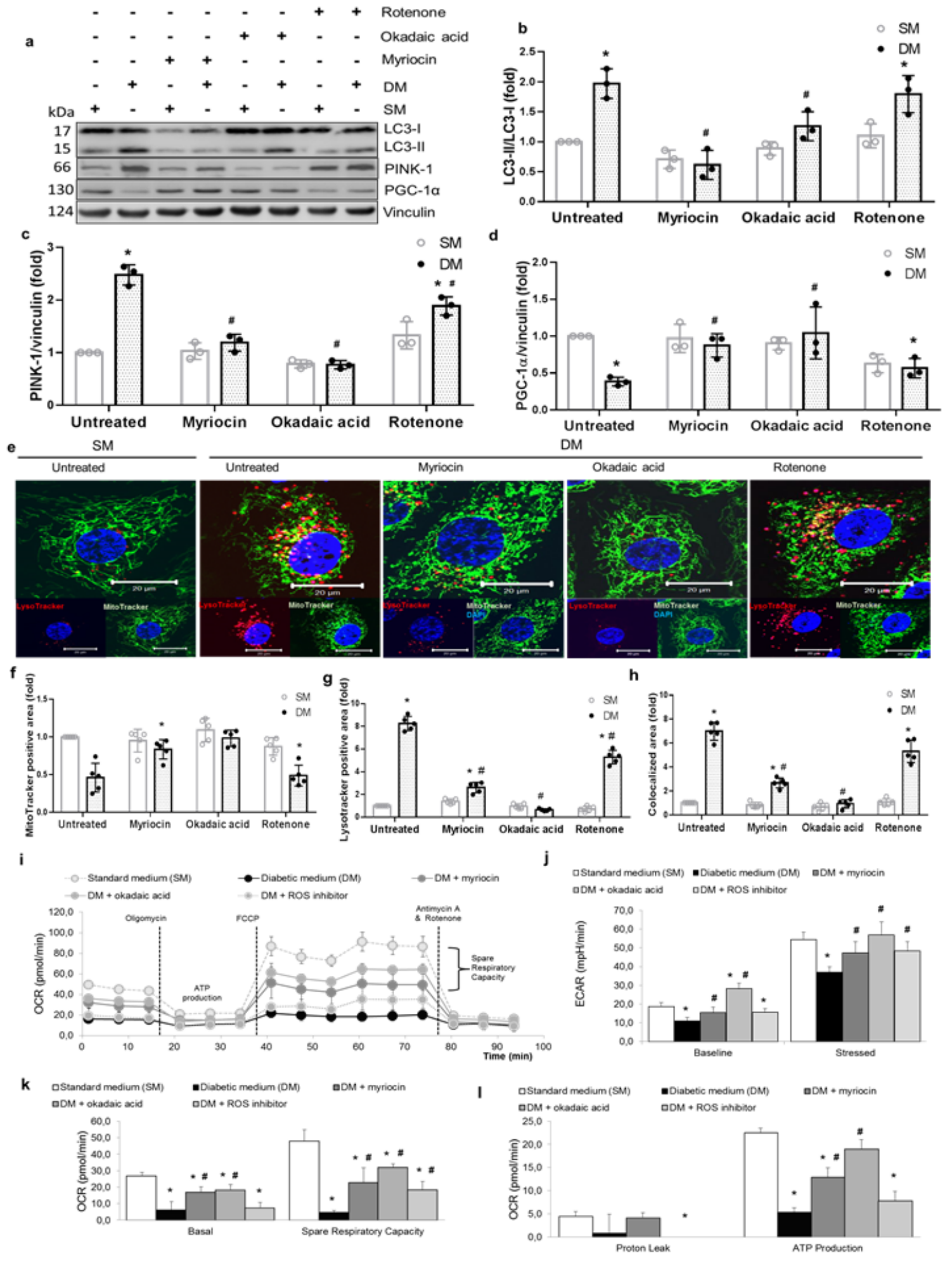

\section{Figure 6}

Rescue the morphological and mitochondrial dynamics in DM. a and b Comparison of the ratio of lapidated LC3-II to non-lipidated LC3-I and the fold change of PINK-1 (a and c) as well as PGC-1a (a and d) between SM- and DM-cultured CMs in the presence or absence of myriocin, okadaic acid, and rotenone 
inhibitors detected by western blot; $n=3$. e Representative immunofluorescence images showing fragmented mitochondria indicted by MitoTracker (green) and lysosomes indicted by LysoTracker (red), Nuclei were stained with Hoechst (blue), and the scale bar represents $20 \mu \mathrm{m}$. Quantification of the positive areas of MitoTracker $(\mathrm{f})$ and LysoTracker $(\mathrm{g})$ as well as the ratio of co-localized LysoTracker- and MitoTracker - positive area (h) in the h-iPSCs-derived-CMs cultured in SM and DM in the presence or absence of myriocin, okadaic acid, and rotenone inhibitor; $\mathrm{n}=5$. Mitochondrial respiration in $\mathrm{CMs}$ cultured in $\mathrm{SM}$ and DM in the presence or absence of inhibitors assayed under basal conditions and stressed conditions. i FA $\beta$-oxidation was determined through measurements of OCR. j Glycolysis determined through measurements of the ECAR. Statistical analysis of basal respiration and respiratory capacity $(k)$ as well as proton leak and ATP production (I); $n=5-8$. * $p<0.05$ compared to SM-CMs and \# $p<0.05$ compared to DM-CMs using two-way ANOVA Tukey's multiple comparisons test.

\section{Supplementary Files}

This is a list of supplementary files associated with this preprint. Click to download.

- GraphicalAbstract.tif

- Onlinemovie4.avi

- Onlinemovie3.avi

- Onlinemovie2.avi

- Onlinemovie1.avi

- Bekhiteetal.Suppl..docx 